\title{
EPILOGUE
}

\section{Being undisciplined: \\ Doing justice to the immensity of human experience}

Nigel Rapport

\begin{abstract}
A review of the volume; an appraisal of the anthropology of Britain as a project. An argument is made along Kierkegaardian lines. Human life is an inward, personal adventure, of each in the face of the other: life is individual and possessed of infinite depth. Conducting social-scientific research (whether 'anthropological' or 'sociological') in a language—verbal, gestural and conventional-with which the researcher is 'at home' enables that individual and inward life, and its public and social dimensions, to be apprehended with a subtlety and sophistication far more difficult to acquire in 'foreign' settings. Anthropology 'at home' is ideally placed to differentiate between the cultural forms of life, the social structures of life, and how these are individually inhabited and personally experienced. To do justice to human life-descriptive, analytic — is to apprehend an immensity-a complexity and contrarietybeyond the delimitings of partial labels and categories, even beyond particular disciplines of study.
\end{abstract}

Keywords

Britain, labels, existence, individuality, world-view, life-project, symbolic interpretation

'What are days for?

Days are where we live'

Philip Larkin, from 'Days’

\section{On labels}

Labels are also where we live, in a way: 'Britain' and 'Wales', 'Anthropology' and 'Sociology'. However, where we live only begins to address issues of how we live: the 'where' that such labels might seem to identify is a superficial one.

The 'where' that someone might ascertain — and assert—in the definition of 'Nigel Rapport' — say, as an 'anthropologist' of 'Welsh' or 'British' (or 'Jewish') extraction-is a place that feels remote from the 'where' that I know myself to come from and live in. It pertains to an exterior knowledge by which 
someone might categorise me and by this classification claim to identify me. Even should these labels of exterior classification be multiplied-'Nigel Rapport', who is also 'male', 'White', 'married' and 'middle-class', who 'supports Arsenal', who works at 'St Andrews University' - the knowledge remains a generalised one. Even should the labels be those I myself suggest'Nigel Rapport', who is an 'atheist', a 'liberal', a 'Zionist', and a lover of 'Bloomsbury' fiction - the knowledge conveyed by the labels as such is superficial compared to the particularities and intimacies of interpretation by which I animate those labels and make them meaningful in my life. The use of labels represents a dialectic between their external imposition and their internal inhabitation. Existence, Kierkegaard (1941, p.118) observed, is an inward, personal adventure of each in the face of the other: life is individual and possessed of infinite depth.

What precisely might this imply for the disciplinarity of 'anthropology' and 'sociology'? The intent of this volume, eloquently enunciated by Cathrine Degnen and Katharine Tyler, is to challenge and disrupt traditional notions of the two disciplines - in particular the notion that an 'anthropology of Britain' is simply the practice of social anthropology 'at home' - and to interrogate a history of relations in British academe of 'studied indifference': anthropology and sociology being closely related yet persistently estranged. Should we not reconsider their relations as mutually constitutive?

A first response, then, can be to assert the personal nature of these labels for their (internal) professional exponents. In this spirit, I might further offer the interpretations below as being, for me, key. 'Sociology', according to Georg Simmel (1971, pp. 27, 32), discloses how:

'[s]ociety exists where a number of individuals enter into interaction; society is interaction. (...) A description of a social situation is an exercise in psychological knowledge'.

The definition is elaborated by Herbert Blumer (1972, pp. 182, 186):

'Instead of the individual being surrounded by an environment of pre-existing objects which play on him and call forth his behaviour, the proper picture is that he constructs his objects on the basis of his ongoing activity. (...) Human society consists of acting people and the life of the society is to be seen as consisting of their actions'.

And finally by Jack Douglas (1977, pp. xiv-xv):

'There is no community, no constraint, no power, when individuals do not build them and maintain them. (...) 
Everyone knows immediately that he is a mass of complex, conflicting, momentarily changing feelings, and that is where he lives'.

As for the label 'anthropology', from Anthony Cohen (1994, pp. 146, 180) I hear that:

'Society is constituted by self consciousness and substantiated by the meanings which conscious selves impute to those received forms. (...) We must make deliberate efforts to acknowledge the subtleties, inflections and varieties of individual consciousness which are concealed by the categorical masks which we have invented so adeptly.'

And then from Tim Ingold (2015, p. 342):

If anthropology stands for anything, it is for the idea that human life cannot be sliced up into discrete layers [psychological, social, biological], for separate study by different disciplines[:] anthropology is the study of human being and becoming, as it were, 'in the round'.'

Finally, I arrive at my own conclusion (Rapport, 2003, p. 75):

'Anthropology is the study of the manifold—direct and indirect, intended and unintended-effects that human beings as individual, energetic things-in-the-world have upon one another.'

It seems that the labels 'sociology' and 'anthropology' can be in habited in such a way that the different terms indicate different histories of institutionalization rather than anything essentially substantive. Each may be said to concern the individual construction and experience of social milieux and cultural traditions, disclosing that sociocultural circumstance where human beings as individual centres-of-energy (driven by their own metabolisms, within distinct embodiments, possessing unique histories of conscious activity-in-the-world) impact on one another's lives.

\section{On experience}

Certainly, this accords with my own research experience, beginning in the rural farming (and tourist-focused) dale of 'Wanet' in north-west England. In Diverse World-Views in an English Village (1993) I examined the way in which beneath 
the cover of the common symbolic forms of daily exchange, individual villagers were set apart in worlds whose environmental features and landmarks, identities and meaning, were of their own creation. It was as if each occupied their own cultural space, while conducting social relations with one another by virtue of words and behaviours that were intrinsically ambiguous: the symbolic was subject to interpretation that was necessarily, individual, personal and private in nature. There was also a sense in which individual villagers were set apart from themselves, for each did not only inhabit one world-view but several, in each of which not only the environing world was different but they were too: as if different people, speaking with different voices, holding different values, with different expectations. When different villagers-Sid and Doris, say (the builder and the farmer for whom I worked) — conversed together the effect was chaotic: not only Sid and Doris talking past each other, using the same words to mean subtly different and often incompatible things, but Sid and Doris also talking past themselves, as different versions of themselves pursued each other across the conversational space, within the 'same' symbolic forms. In the apparently small and homogeneous social setting of an English village, those born and bred there as well as those newly arrived retirees, second-home owners and tourists occupied not one culture but a plethora, as a multiplicity of private contexts collided, and individuals construed world-views and life-projects that owed their nature and their content not to what was externally derived or imposedby way of community, profession or class, discourse or habitus, nationality or ethnicity, religion or gender-but to what was personally invented.

This being the nature of social reality in Wanet, how was it best represented? In The Prose and the Passion: Anthropology, Literature and the Writing of E. M. Forster (1994), I wondered how the case of literature-in particular the 'social novelist'-might allow anthropology better to come to terms with the subtleties of its own data, doing justice to life's personalism, complexity, transitoriness, diversity, ambiguity, distortion and depth. The key was creativity: of informants who made individual lives for themselves, and of their anthropologists who might transmute an experience of that individuality into authentic, 'crafted' accounts.

\section{On category-thinking}

I recognise however, mutatis mutandis, that the 'humanistic' or 'existential' or 'cosmopolitan' or even 'liberal' way in which I might justify having inhabited the labels 'anthropology' and 'sociology' need not correspond to others', whose orientation may instead be 'functionalist' or 'structuralist' or 'post-structuralist', 'Marxian', 'Foucauldian' or 'Geertzian', and so forth. But the lesson to be drawn, as I understand it, concerns the dangers and delimitings of 'categorythinking'. The categorial label is not the extent of the existence it purports to identify and know; the label may barely scratch the surface of the conscious experience it classifies. While 'anthropology' and 'sociology', and 'British', 
'Welsh', 'Jewish', 'atheist', have the convenience of appearing to order the world cleanly and definitively, personal consciousness nevertheless escapes: in its singularity, its complexity, and its fluidity.

This was further brought home to me in a later period of participantobservation, working as a porter at Constance Hospital, in the Scottish city of 'Easterneuk' (published as Of Orderlies and Men: Hospital Porters Achieving Wellness at Work (Rapport, 2008)). Some 130 porters were employed at Constance, a large state-funded teaching hospital with a total workforce of thousands. Not being medically trained, the porters occupied a somewhat lowly position in the organization; portering tasks-ferrying patients across the hospital, delivering mail, transporting body parts, bodily substances and dead bodies - called for physical stamina more than any other skill. However, while much social interaction appeared hierarchical, in their lodge (or 'buckie'), two cramped rooms below the level of the main hospital concourse, the porters kept up a commentary on life-the hospital, the wider Easterneuk world, one another-whose ethos was critical and humorous. Their commentary called into question so-called expert claims to status, skill and even identity. Being 'a man' (all but two of the porters were male) was surely an easily identifiable matter, and 'manliness' supervened upon the conceits of academic medicine with its fetish for rank, class and ritual: Constance Hospital's world of work was surely insignificant in the context of a man's life of fun, 'crack', joking, drinking, fighting, sex and football. The routine in which the porters partook while working at Constance Hospital, including the massification that the label and the category 'porter' conveyed, may not one that they escaped at work but it was one that they were not responsible for inhabiting and animating according to their own (diverse) wills. The porters skirted creatively and ludically around this (and other) labels that might seek to define them: skilled in the labels' use and also abuse; above all, remaining tricksy with regard to which might truthfully apply to themselves, as individuals and as members of a professional group-if anything at all.

\section{On expertise}

Given the irreducible personalism of consciousness, it is always an imposition (in all senses of that word: presumptuous; an assertion of power; often unwelcome) to perceive the human world categorially rather than attempting to know its individual centres-of-energy in their own terms (Rapport, 2012). The most difficult thing is also the most necessary thing: to aspire to an understanding of the individual other and then do justice representationally to that otherness: to find the symbolic forms that do not compromise and corrupt 'the subtleties, inflections and varieties' of individual conscious selfhood. To return to the exhortations of Anthony Cohen (1978, p. 450): woolly generic categories like 'society', 'culture', 'class', 'The British', 'Women', whether externally imposed or self-imposed, entail reductions to lowest common 
denominators of identity; individuals appear merely as components or fractals of larger collective entities whose characters they embody. This is an unsubtle and erroneous accounting of consciousness-and hence of the social and cultural worlds to which self conscious individuals give rise. Common symbolic forms, labels and categories do not betoken common meanings. It is necessary to 'treat societies, cultures, as barely generalizable aggregations of difference rather than as fictive matrices of uniformity' (Cohen, 1993, p. 213).

The references to Anthony Cohen are not incidental, given his seminal role in encouraging an anthropology of Britain (1982, 1986, 1987). Which returns us to the issue of the distinctiveness of that anthropology-or sociology — of Britain. What can we expect to achieve as, under the direction of Cathrine Degnen and Katharine Tyler, this distinct area of inquiry looks outward, geographically and also interdisciplinarily? What specific ethnographic, theoretic, philosophic and social-policy insights do we hope to provide?

The bullish proposition with which I warranted my own edited collection in 2002, British Subjects, was that an anthropology 'at home' in Britain had the potential merit and significance to make it paradigmatic of disciplinary concerns. All that was human could be discerned and interrogated in Britain, while its study could potentially set the disciplinary standard for sensitive ethnography and for complex analysis alike. My argument concerned competency (rather than any essentialistic notion of 'cultural belonging'). An anthropologist thoroughly at home in British linguistic denotation, with an expertise in the formulaicism and normative proprieties of cultural forms of interaction, was potentially more able to sensitize themselves to the connotative: to pick up clues concerning what lay beneath the surfaces of exchange, to appreciate its ambivalences and ambiguities, and thus to gain access to the most intimate, intricate and significant aspects and levels of being-in a sociocultural milieu and being-with others (Rapport 2002, pp. 6-8). 'Si bis faciunt idem non est idem' ('If two people do the same thing it is not the same thing') is the Classical aphorism (as cited by George Devereux (1978, p. 125)) that might be taken as a shorthand for the complex realities of human social life: the radical distinction between surfaces and depth (public and private, exteriority and interiority) that provides sociality with its fundamental character. A culturalcum-linguistic competency enables the researcher who is 'at home' in British milieux to reach beyond the surface of cultural categories, labels and classes to individual and human depths. One discerns and discloses the dynamics of how the show of cultural forms, the surface, is existentially inhabited and socially enacted.

\section{The volume}

The work contained in the present volume significantly extends this tradition of 'expertise'. To rehearse it in brief, Cathrine Degnen and Katharine Tyler's 
work on 'intersectionality' and 'intersection' in English mining communities (and in British academe) resonates with the Gluckmanian concept of 'crosscutting ties', as incisively applied to the fishing communities of Lewis by Peter Mewett (1982). In an individual life a range of discursive regimes and labels can meet. In contemporary Britain, people may find themselves positioned according to questions of nationhood, race and ethnicity, post-colonialism and post-industrialism, regionality and migration, social class, age and gender, the environment-and academic disciplinarity. These can each convey a different stigmatisation and inequality: their intersecting and cross-cutting give rise to subtly unique instances of disadvantaging and discrimination.

Alexander Smith's examination of the meaning of Britishness in relation to 'the Scottish Question' recalls Susan Lewis's (2002) account of the 'national identity' and freedom from 'colonialism' that are espoused on the Isle of Man in celebrating a 'National Day'. 'Britain' is contested space, not simply a site to know, and, in the wake of the 2014 Scottish independence referendum, undertaking an 'Anthropology of Britain' is also a political work; those who reckon themselves non-British now reside within the borders of the United Kingdom. For Smith, the conditions of knowing 'Britain' and identifying 'Britishness' are shaped by a relation with otherness: British subjects here vis-àvis British subjects elsewhere (and in former colonies) and also 'non-British subjects'. An 'anthropology of Britain' concerns a de-territorialised site of the imagination rather than a taken-for-granted geography.

Laura Jeffery's reflection on the agency of members of the extended Chagossian community - displaced forcibly from the British Overseas Territory of the Chagos Islands - echoes the efforts of Allison James (2002) to disinter the hidden agency of children, equally constructed as a dependent population, yet authors of their own lifeworlds. Jeffery highlights the way in which, from homes in Crawley, Manchester and London, the migrants construe their displacement both in terms of their victimhood and their choice. Their experience reverberates as forced and voluntary, reactive and proactive, depending on political purpose and personal situation.

Gillian Evans registers the social and cultural dynamics of inequality with which the English working class is faced. Her identifying of a sociality, valueset and scheme of action that resist rather than accept what the middle and upper classes might legitimate as 'culture' calls to mind the work of Ronald Frankenberg (1957) in the slate-mining and farming village of Pentrediwaith. For Frankenberg, men and women were locally divided, culturally, due to the differential extents of their integration in the wider English-speaking industrial economy. For Evans, British classes are culturally divided on the basis of distinct investments in the discourse of multiculturalism. The appeal of the BNP, and now UKIP, is a kind of cultural nationalism that demands recognition for the neglected 'indigenous people of England': the working class 
reconfigures itself as distinctly white, and thus invents a new, resistant political collective.

Insa Koch's work on a council estate in south-east England focuses on voting, and how formal electoral processes thought to be central to the functioning of Britain as a democracy are increasingly eschewed by those who see themselves-instead —as members of the-housing-estate-as-collectivity. Loyalty to this socially and economically deprived space demands 'disloyalty' or active distantiation from an 'a-social' national politics, politicians and political media. One recalls Saugestad Larsen's (1982) work on the legitimation of religious communities in Northern Ireland through their 'performative positioning' relative to larger, apparently external, political structures. It is local networks of support and care to which affective relations belong.

Katherine Smith's account of life on a Manchester housing estate evinces a different kind of agency. To live in Harpurhey is both to 'be poor' and attend the Job Centre - to be the 'worthy person', as defined in governmental social policy, who would achieve independence from welfare benefits-but also to 'be fair': to partake in a discourse which recognises, in a cosmopolitan way, the human identity and individual agency of all. One performs 'being poor' for functional ends and one performs 'being fair' as acts of transcendence of any social categorization. Reminiscent of Andrew Irving's (2010) work on the 'everyday' morality of living with HIV/AIDS-while marginal to a more conventional and normative life-course-Smith describes a moral economy of 'fairness' surviving scarcity, austerity and uncertainty about the future. The discourse serves to cement notions of personal dignity as well as a belonging and interdependency that speak to a broader humanity.

Sarah Winkler-Reid's account of notions of 'success' among teenage pupils in a secondary school in London, and of a diversity of ways in which 'doing one's best' is successfully articulated even within a supposedly hegemonic, 'neoliberal' auditory framework, echoes Colin Lacey's (1970) ethnography of a Manchester grammar school. Lacey disclosed how the 'system' of class hierarchy in the school and the wider society appeared to predispose 'working-class' pupils to relative educational failure: the significant variable, however, was the extent to which individuals were prepared, psychologically, to be satisfied with lower attainment. Winkler-Reid describes how 'everyday actions exceed and cut across discursive formations that insist on comparison and grading': notions of the incommensurate worth of individual pupils were emphasised by the school, foregrounding different aspects of identity and relationality, and instantiating relations of care.

Richard Irvine's work on the different - contested and conflictingtemporalities in whose terms human life can be seen as being lived chimes with Malcolm Chapman's (1992) critical interrogation of the contested temporality surrounding the construction of 'Celtic' identity, and its supposed continuity and longevity. For Irvine, the 'fenland' of East Anglia, land transformed from 
sea and shifting marsh, has a time-depth that warrants local notions of the 'Anthropocene'- of an anthropogenic landscape-but this also serves to obscure a longer term record of flux. There is a temporal disjuncture between the anthropogenesis of the fenland and 'deep time' - the geological history whose temporal horizons dwarf the drainage ditches and fields - wherein the fens have 'always' been 'temporary land'.

Lastly, Andrew Whitehouse's writing on environmental phenomenology and how British bird sounds resonate with people's senses of wellbeing in places, times and seasons, recalls John Gray's (2000) work on how shepherds are 'at home in the hills'. For Gray, hill-sheep fuse people, space and way of life together as a kind of being-in-place; for Whitehouse birds and their sounds, in an ongoing cycle of presence and absence, give rise to a human dynamic of how particular activities, seasons and times of day are habitually experienced. Hearing birds is part of an 'emergent experiential aesthetics': lives, activities and space drawn together in 'authentic' ways, both locally appropriate and ethical.

\section{Envoi}

And the volume points forwards again. Disciplines like anthropology and sociology might intersect, Degnen and Tyler argue, so as to provide an emergent engagement with human social life: grounded theory (anthropology) plus applied theory (sociology); proceeding from particular to universal (anthropology) and from global to local (sociology), sensitive to cultural forms of life (anthropology) and to institutional structures (sociology).

Urging such 'blurring of genres' has been a provocation since the 1980s' 'Writing Culture' debate (Geertz 1983); indeed, Gregory Bateson (1959) was proposing even before that the 'delimitation of disciplines' (through labels such as 'psychology', 'sociology' and 'history') be seen as a 'tragic error' if the aim was to apprehend the immensity of human experience: its 'vast intricacy', complexity and contrariety. 'Everything human endlessly resolves itself in contradiction', Kierkegaard observed (1958, pp. 117-8). It is in this case that epistemological pluralism - deploying together a diversity of understandings of the human condition-and representational pluralism — practising manifold ways of inscribing the human-surely offer the best means available to elucidate a human nature and its individual substantiations (Rapport 1997). 


\section{References}

Bateson, G. (1959). Anthropological theories. Science, 129, 294-8.

Blumer, H. (1972). Society as Symbolic Interaction. In A. Rose (Ed.), Human

Behaviour and Social Processes (179-192). London: Routledge and

Kegan Paul.

Chapman, M. (1992). The Celts. London: Palgrave Macmillan.

Cohen, A. (1978). "The same but different": The allocation of identity in

Whalsay, Shetland. Sociological Review, 26(3), 449-69.

_-(Ed.) (1982). Belonging. Manchester: Manchester University Press. (Ed.) (1986). Symbolising Boundaries. Manchester: Manchester University Press.

(1987). Whalsay. Manchester: Manchester University Press.

(1993). The Future of the Self: Anthropology and the City. In A. Cohen

and K. Fukui (Eds), Humanising the City? (201-221). Edinburgh:

Edinburgh University Press.

(1994). Self Consciousness. London: Routledge.

Douglas, J. (1977). Introduction. In J. Douglas and J. Johnson (Eds), Existential Sociology (3-74). Cambridge: Cambridge University Press.

Frankenberg, Ronald (1957). Village on the Border. London: Cohen and West.

Geertz, C. (1983). Local Knowledge. New York: Basic.

Ingold, T. (2015). Dropping the social. Social Anthropology, 23(3), 341-2.

Irving, A. (2010). Everyday Adventures in London. In S. Williksen and N.

Rapport (Eds), Reveries of Home: Nostalgia, Authenticity and the

Performance of Place (165-186). Newcastle: Cambridge Scholars.

James, A. (2002). The English Child: Toward a cultural politics of childhood. In

N. Rapport (Ed.), British Subjects (143-162). Oxford: Berg.

Kierkegaard, Søren (1941 [1846]). Concluding Unscientific Postscript.

Princeton: Princeton University Press.

- (1958). The Journals of Kierkegaard 1834-1854. Glasgow: Fontana.

Lacey, C. (1970). Hightown Grammar. Manchester: Manchester University Press.

Larkin, P. (1988). Collected Poems. London: Faber.

Larsen, S. (1982). The Glorious Twelfth: A ritual expression of collective Identity. In A. Cohen (Ed.), Belonging (278-291). Manchester:

Manchester University Press.

Lewis, S. (2002). National Day: Achieving collective identity on the Isle of

Man. In N. Rapport (Ed.), British Subjects (49-65). Oxford: Berg.

Mewett, P. (1982). Associational categories and the social location of relationships in a Lewis crofting community. In A. Cohen (Ed.), Belonging (101-130). Manchester: Manchester University Press.

Rapport, N. (1993). Diverse World-Views in an English Village. Edinburgh: Edinburgh University Press. 
- (1994). The Prose and the Passion: Anthropology, Literature and the Writing of E. M. Forster. Manchester: Manchester University Press.

- (1997). Edifying Anthropology: Culture as Conversation, Representation as Conversation. In A. James, J. Hockey and A. Dawson (Eds), After Writing Culture (176-93). London: Routledge.

- (2003). I am Dynamite: An Alternative Anthropology of Power. London: Routledge.

-(2008). Of Orderlies and Men: Hospital Porters Achieving Wellness at Work, Durham NC: Carolina Academic Press.

- (2012). Anyone, the Cosmopolitan Subject of Anthropology. Oxford: Berghahn. 


\section{RUBBISH}

They might elaborate how from the moment the individual energy source begins moving in its environment (in the womb) and becoming itself, a unique history of embodiment, of worldly engagement, unfolds and grows which compasses its own logics, its own habits, its own ways of doing and being, and its own purposes. Each human being will react to other things-in-the-world in ways that are not determinable: how each will affect others is difficult, if not impossible, to predict. For three reasons: first, because each is set upon its own life-course, each engaged in furthering a life-world, a 'life-project', whose direction and logic has been distinct from the moment 'it' began. Second, because each engages with others from the position of outsider: each is dependent on bodily sense-making apparatuses which are discrete and distinctive to itself and which imbue it with its own perspective on the world and no other. And third, because the sense-making procedures of each is characterized by a creativity-even randomness or gratuitousness - which makes their generation of perspectives unpredictable even to themselves (cf. Rapport, 2001, 2008a).

_(2001) 'Random Mind: Towards an Appreciation of Openness in Individual, Society and Anthropology', The Australian Journal of Anthropology, 12(2): 190-220.

(2008a) 'Gratuitousness: Notes towards an Anthropology of Interiority', The Australian Journal of Anthropology, 19(3): 331-49.

\section{'Threads snap': On representing an anthropology of Britain}

The following extract comes not from a Forster text but an Oscar Wilde one, The Picture of Dorian Gray. (Wilde is similarly, I would posit, a writer of British auto-ethnography.) Here, Dorian witnesses a conversation between the Duke and Duchess of Monmouth, 'Henry' and 'Gladys', that turns to the nature of identity, both national and individual (Wilde 1965:486-7). Henry discloses his dislike of labels, protesting: 'From a label there is no escape!'. Gladys retorts:

““You don’t like your country, then?” she asked.

"I live in it."

"That you may censure it better." (...) She shook her head. "I believe in the race," she cried.

"It represents the survival of the pushing."

"It has development."

"Decay fascinates me more."

"What of Art?" she asked.

"It is a malady."

"Love?" 


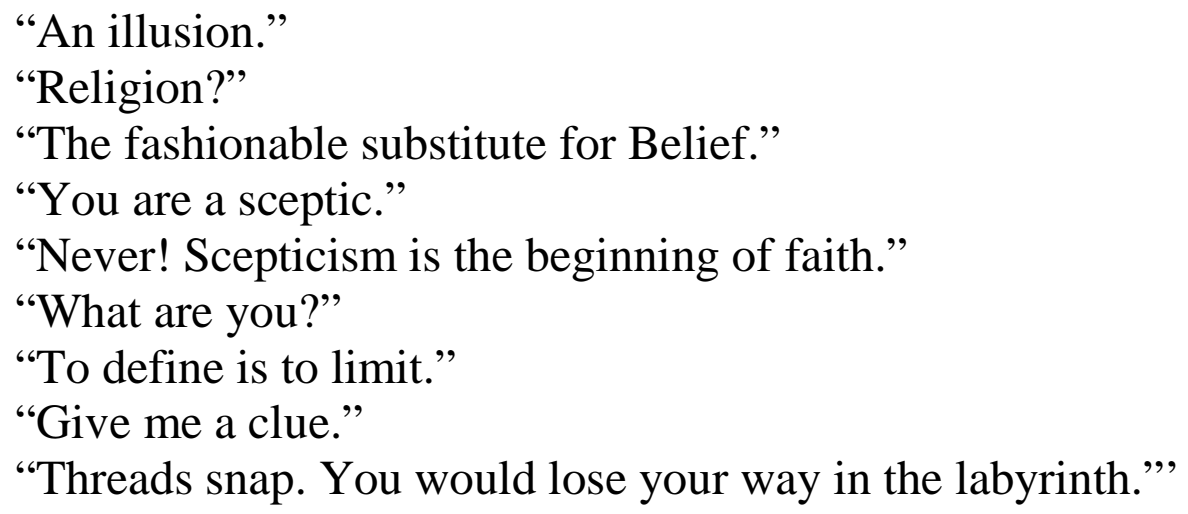

The wariness with regard to definition - the warning that 'threads snap' when it is expected that an individual can be followed along an easily traceable, external line of character-I bear in mind when offering the ethnographic extract below.

Amid a busy buckie, Arthur begins a conversation with Steve, one of the small number of English porters employed at Constance. One of Steve's major pastimes outside work is golf, including organising golfing trips abroad for his gang of drinking mates, for whom he acts as unofficial treasurer:

Steve saunters into the buckie ostentatiously counting a wad of banknotes in his hand.

Arthur: 'Cor blimey!'

Steve: 'No! I say, “Watch it mush”. I’m not from south London, so don't confuse me with that lot... It's bad enough being from London!' Arthur: 'It's bad enough being from England!'

Steve: 'Don't start, now! Nor you, Spike-Head [Steve indicates Arthur's friend, Michael (who sports a crew-cut, and who has broken into a grin)]'.

Arthur [putting on a cockney accent]: 'You South London wanker! Walthamstow wanker!'

Steve turns his attention again to his wad of notes: 'That's $£ 210$ !' Oliver [with a note of jealousy in his voice]: 'A bit dangerous carrying that on you by the front-door corridor of the Hospital on a Wednesday!'

Steve: 'No one will take this off me! None of you boys could take it off me [the watching group of porters remains silent]... Cos I'd set you onto them, Oliver!' [He laughs]

Oliver [grinning]: 'Aye: for a small fee!'

Steve: 'Yeah, £210!'

What strikes me in this extract is the way that Arthur and Steve, similarly to Oscar Wilde's character Henry, show ambivalence towards the definitions that labels convey. In Henry's case the labels concerned 'scepticism', 'religion', 'art', 'love', 'country' and 'race'. Between Arthur and Steve they are 'London', 
'south London', 'Walthamstow', 'England' and 'wanker'. But the porters practice their ambivalence differently to Henry. As well as distancing themselves from certain labels, they energetically impose them on others. Arthur would have Steve as a cockney, a wanker, English—all of which, he implies, are remote from who he is. Steve disparages those from south London, and even London (now that he has moved north); also those 'boys' who do not have wads of banknotes to carry round, nor the strength to remove them from those who have, and who finally, it is implied, will not be party to the spending of the money. Most significantly, however, I feel that 'threads snap': that who Steve and Arthur present themselves as being has as much a labyrinthine character to it as was the case with Henry. There is no essentialism here in the claims made either regarding self or other. Arthur's disparaging of Steve as 'other' is, then, playful because they are also workmates and both are residents of Easterneuk. Arthur's intoning of 'Cor blimey' and 'Walthamstow wanker' - as with Steve's designation of 'Spike-Head'-are also manifestations of intimate knowledge and appreciations of individuality. Steve's ostentatious monetary display is also a request for his fellow's notice and valuing of their esteem, as well as a demonstration of trust: he is safe with them. Steve's admission of 'weakness'that being from London is bad enough—also signals his sense of security, as does his invitation to a diminutive Oliver to be his paid protector: weaknesses can be admitted here in the 'backstage' space of the buckie.

In short, the extract reveals Surely, the inappropriateness of these labels as defining anything essential about them, Steve and Arthur insinuate, equally applies to the categorization that would see them as simply and essentially 'porters'?

Bailey, F. G. (ed.) (1971) Gifts and Poison, Oxford: Blackwell.

\section{Envoi}

This is emancipatory in a political way as well as an epistemological one. The politicisation of identity that has accompanied globalisation-the assertions that 'cultures are not options' (Parekh 1998:212), or other such communitarian claims-points up its own falsities. The need to assert so vehemently claims of essential membership by individuals of collective categories - ethnicities, religions, nations - is a kind of special pleading: vehemence born from desperation. It is increasingly clear that the individuals in movement across the globe are ontologically distinct from the communities that (in the politics of multiculturalism) are supposedly responsible for their identity and being. Parekh, B. (1998) 'Cultural Diversity and Liberal Democracy' in G. Mahajan (ed.) Democracy, Difference and Social Justice, 202-27, Delhi: Oxford University Press. 